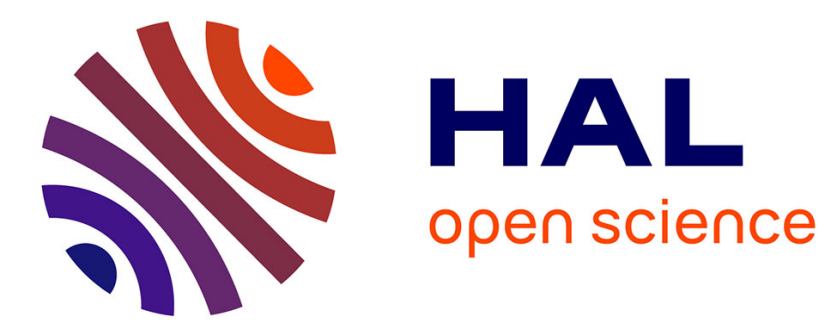

\title{
Dyskalemia: a management problem for students.
}

Lisa Senninger, Laure Abensur Vuillaume, Luc Frimat, Nicolas Girerd, Zohra

Lamiral, Patrick Rossignol, Jean-Marc Boivin

\section{To cite this version:}

Lisa Senninger, Laure Abensur Vuillaume, Luc Frimat, Nicolas Girerd, Zohra Lamiral, et al.. Dyskalemia: a management problem for students.. Fundamental \& Clinical Pharmacology, 2020, 35 (2), pp.473-484. 10.1111/fcp.12621 . hal-03025955

\section{HAL Id: hal-03025955 \\ https://hal.univ-lorraine.fr/hal-03025955}

Submitted on 26 Nov 2020

HAL is a multi-disciplinary open access archive for the deposit and dissemination of scientific research documents, whether they are published or not. The documents may come from teaching and research institutions in France or abroad, or from public or private research centers.
L'archive ouverte pluridisciplinaire HAL, est destinée au dépôt et à la diffusion de documents scientifiques de niveau recherche, publiés ou non, émanant des établissements d'enseignement et de recherche français ou étrangers, des laboratoires publics ou privés. 


\title{
Dyskalemia: a management problem for students
}

\author{
Lisa Senninger ${ }^{1}$ Laure Abensur Vuillaume ${ }^{2,3}$, Luc Frimat ${ }^{2}$, Nicolas Girerd $^{2}$, Zohra Lamiral ${ }^{2}$, Patrick \\ Rossignol $^{2}$, Jean-Marc Boivin ${ }^{2}$ \\ ${ }^{1}$ Université de Lorraine-Nancy (France) \\ ${ }^{2}$ Université de Lorraine, Inserm, Centre d'Investigations Cliniques- Plurithématique 14-33, \\ and Inserm U1116, CHRU, F-CRIN INI-CRCT (Cardiovascular and Renal Clinical Trialists), \\ Vandoeuvre (France) \\ ${ }^{3}$ Emergency Departement, Regional Hospital Metz-Thionville, France
}

Corresponding author: jm.boivin@chru-nancy.fr

Phone number: 0033383157311

Keywords: Hypokalemia, hyperkalemia, potassium, heart failure, renal failure, general medicine, students

Words count: 3833

\section{Abstract}

1

Background: Although dyskalemia is common, its management can be problematic for students and general practitioners, especially when it occurs in patients with heart and renal failure. The basic academic knowledge of general medicine students, who have often not yet encountered clinical situations of dyskalemia, remains unclear in this regard.

Objectives: The purpose of this study was to evaluate the knowledge and reflexive practices of general medicine students in regard to dyskalemia.

Methods: A cross-sectional survey, based on a self-questionnaire, of all of the students enrolled in general medicine studies at the Faculty of Medicine at the University of Nancy (France) at the end of their degree. The students were asked questions pertaining to specific 
clinical situations. The answers were compared to the information provided in the medical curriculum as well as to the relevant European guidelines.

Results: We collected 290 of the questionnaires (participation rate: 81.2\%). The hyper- and hypo-kalemia thresholds considered pathological (3.5-5.0 mmol/L) were known by $78 \%$ and $67 \%$ of the students, respectively. The perception of danger in case of severe hypokalemia was underestimated by $62.7 \%$ of them. In most cases, the proposed management of hyperkalemia in heart and renal failure did not comply with the relevant guidelines. The students tended to favor permanent discontinuation of the administration of converting enzyme inhibitors (ACE) and/or mineralocorticoid receptor antagonists (MRA) without considering the need for their reintroduction (51.6\%). Sodium polystyrene sulfate was frequently seen as an appropriate first-line treatment for hyperkalemia (45\%).

Conclusions: The knowledge and competence of general medicine students appear to be lacking for hyperkalemia in heart and renal failure, and they are long way from full compliance with the relevant European guidelines. Exposure to complex clinical situations as part of the medical curriculum, therefore, seems essential to improve the way dyskalemia is managed in France.

\section{Strengths and limitations of this study}

1) The main strength of this study lies with the use of an open-ended questionnaire, which ensured that there were no leading questions and not suggest possible answers to the situations described.

2) The second strength: The questionnaires were filled out in the presence of a friendly and neutral team, without direct intervention but with immediate availability of assistance if required (self-administered questionnaire).

3) The third strength: Methodological bias was minimized by providing resources to organize the task of collecting, analyzing, and processing the information.

4) The first limitation: Sample selection bias cannot be fully ruled out, although we are confident that we were able to ensure adequate representativity of the population of students enrolled in French general medicine studies.

5) The second limitation: we cannot exclude that the respondents were the most motivated students, however we had a high response rate of over $81 \%$. 


\section{Background}

Dyskalemia (hypokalemia and hyperkalemia) are potentially dangerous conditions $(1,2)$. It is mostly encountered in high-risk patients (e.g., with heart failure, renal failure, cardio-renal syndrome, diabetes, hypertension) but also, occasionally and unexpectedly, people without comorbidities (3). Management is not consensual according to the guidelines in place, and the thresholds for hypokalemia and hyperkalemia are not universal (4).

Many studies of patients with heart failure have focused on the association between blockers of the renin-angiotensin-aldosterone system (RAAS) and anti-aldosterone, as all may trigger hyperkalemia and can be a source of problems, particularly for general practitioners (5-8). In contrast, loop diuretics may lead to hypokalemia or dehydration, which can be difficult to manage in the context of renal insufficiency (9).

It is not precisely known how general practitioners deal with dyskalemia, especially as there is not a specific decision tree to guide them in this regard. While the way they go about this is presumably based on their prior experiences and on interactions with other specialists, the basic academic knowledge and skills of general medicine students who have not yet encountered clinical situations of dyskalemia remains largely unknown.

\section{Methods}

\subsection{Objectives}

The main objective of this study was to evaluate the knowledge of French general medicine students regarding dyskalemia.

The secondary objective was to evaluate how they manage clinical situations involving dyskalemia.

\subsection{Type of study}

All of the students (from the first to the third year of study) at the end of their general medical studies in Nancy, France, $(\mathrm{N}=357)$ were asked to answer a self-questionnaire, kind of like 
100 Durieu et al, regarding the perception of adverse drug reactions (10) during their final exams 101 in June 2017. The questionnaire was in two parts: the first two questions focused on the

102

103

104

105

106

107

108

109

110

111

112

113

114

115

116

117

118

119

120

121

122

123

124

125

126

127

128

129

130

131

132

133 perception of dyskalemia and the next three questions were clinical situations with open answers, to avoid influencing the answers. The questionnaire was constructed in such a way that the study reflects a general medicine context, where more information is not available at the start usually limited to the only information available in the medical report. The objective was to evaluate the student's "reflex" management without suggesting a list of predefined answers so as not to influence the student. The answer was open-ended.

The questionnaire was first tested with ten students to ensure that it was fully understood in the first round and that the answers were stable in the second round, as well as to ensure the validity of the questionnaire (11).

The results were analyzed by collecting the terms in verbatim form. Thus, "monitoring under scope", "intravenous hydration", and "calcium gluconate" were classified under the term "hospitalization/emergency" as these treatments are not available in the public health care system; "taking vital signs" and "blood pressure measurement" were classified under "assessment/clinical examination". The analysis and classification of the verbatim statements were performed after comparing the independent analyses of two authors (S. L. and B. J.M.) followed by arbitration.

The answers were then compared to the treatment stipulated in the medical curriculum (from the University College of Nephrology Teachers) (12), and then to the treatment recommended by the relevant European guidelines $(12,13)$. The answers were stratified by the years of study.

\subsection{Statistical analysis}

The analyses were performed using SAS® R9.4 software (SAS Institute, Cary, NC, USA). The bilateral significance level was set at $\mathrm{p}<0.05$.

All of the students' answers, which were generally binary, were proportionally described in the general population according to the year of study. Those regarding the hyperkalemia and hypokalemia thresholds were categorized; their distribution was analyzed according to the year of study. 
134 The proportion of answers that were in keeping with the curriculum and the relevant 135 European recommendations/literature data/expert opinions were based on indicator variables.

136 These were created from the students' answers, as well as the information in the curriculum 137 and the European guidelines.

138 Each indicator variable was rated "1" if the student's answer was in keeping with the medical 139 curriculum or the guidelines, and "0" if the answer was non-compliant.

141 The results were compared according to the years of study using Fisher's exact test, and the 142 thresholds of dyskalemia according to the years of study were compared using a Chi ${ }^{2}$ test of 143 homogeneity.

\section{Results}

The percentage of questionnaires returned was $81.2 \%(n=290 / 357)$. Three questionnaires were partially completed and were not included (Figure 1).

\subsection{Description of the population}

150 The general medicine students who responded to the questionnaire were evenly distributed 151 among the three years of internship (33.8\% in the first year, 35.9\% in the second year, and $15230.3 \%$ in the third year). 
171 The students considered a mean hyperkalemia of $5.1 \mathrm{mmol} / \mathrm{L}$ to be pathological. The

172 minimum hyperkalemia value proposed by one student was $3.5 \mathrm{mmol} / \mathrm{L}$ and the maximum

173 value was $6.5 \mathrm{mmol} / \mathrm{L}$. The mean hypokalemia considered to be pathological by the students

174 was $3.4 \mathrm{mmol} / \mathrm{L}$ (minimum $2.5 \mathrm{mmol} / \mathrm{L}$ and maximum $3.8 \mathrm{mmol} / \mathrm{L}$ ). (table 1 )

\begin{tabular}{|c|c|c|c|c|c|c|c|c|c|}
\hline \multirow[b]{2}{*}{ Year } & \multirow[b]{2}{*}{$\mathrm{n}=287$} & \multicolumn{4}{|c|}{ Hyperkalemia threshold } & \multicolumn{4}{|c|}{ Hypokalemia threshold } \\
\hline & & $\begin{array}{c}K<5 \\
17(5.9 \%)\end{array}$ & $\begin{array}{c}K=5 \\
192(66.9 \%)\end{array}$ & $\begin{array}{l}5<K \leq 5.5 \\
71(24.7 \%)\end{array}$ & $\begin{array}{r}\mathrm{K}>5.5 \\
7(2.4 \%)\end{array}$ & $\begin{array}{c}K<3 \\
8(2.8 \%)\end{array}$ & $\begin{array}{l}3 \leq K<3.5 \\
53(18.5 \%)\end{array}$ & $\begin{array}{c}K=3.5 \\
224(78 \%)\end{array}$ & $\begin{array}{c}K>3.5 \\
2(0.7 \%)\end{array}$ \\
\hline $1^{\mathrm{st}}$ & $\mathrm{n}=97$ & $\begin{array}{c}10 \\
(18.2 \%)\end{array}$ & $72(74 \%)$ & $11(11.3 \%)$ & $4(4.1 \%)$ & $4(4.1 \%)$ & $16(16.5 \%)$ & $76(78.4 \%)$ & $1(1 \%)$ \\
\hline $2^{\text {nd }}$ & $\mathrm{n}=103$ & $6(5.8 \%)$ & $61(59.2 \%)$ & $34(33 \%)$ & $2(1.9 \%)$ & $3(2.9 \%)$ & $17(16.5 \%)$ & $82(79.6 \%)$ & $1(1 \%)$ \\
\hline \multirow[t]{2}{*}{$3^{\text {rd }}$} & $\mathrm{n}=87$ & $1(1.1 \%)$ & $59(67.8 \%)$ & $26(29.9 \%)$ & $1(1.1 \%)$ & $1(1.1 \%)$ & $20(23 \%)$ & $66(79.5 \%)$ & $0(0 \%)$ \\
\hline & & \multicolumn{4}{|c|}{$p=0.0005$} & \multicolumn{4}{|c|}{$p=0.85$} \\
\hline
\end{tabular}

178 Table 1: Hyperkalemia and hypokalemia threshold (mmol/L) according to the years of 179 study.

181 There was a statistically significant difference in the hyperkalemia thresholds for the different 182 years of study $(\mathrm{p}=0.0005)$. Nearly a quarter of the students rated the threshold for 183 hypokalemia as being strictly below $3.5 \mathrm{mmol} / \mathrm{L}(21.3 \%, \mathrm{n}=61 / 287)$ (Table 1).

184 The kalemia thresholds considered to be pathological according to the curriculum (11) and the 185 relevant guidelines (13) were the same (hypokalemia $=3.5 \mathrm{mmol} / \mathrm{L}$ and hyperkalemia $=5.0$ $186 \mathrm{mmol} / \mathrm{L})$. This hypokalemia threshold was indicated by $78 \%(\mathrm{n}=224 / 287)$ of the students, 187 while this hyperkalemia threshold was indicated by $66.9 \%(n=192 / 287)$ of the students, and $18859.6 \%(n=171 / 287)$ of the students correctly identified both of these pathological thresholds.

\subsubsection{Perception of danger}

191 More than half of the general medicine students thought that severe hyperkalemia was more 192 of a "concern" than severe hypokalemia $(60.3 \%(n=173 / 287)$ vs. $26.5 \%(n=76 / 287))$; for 
193

194

195

196

197

198

199

200

201

202

203

204

205

206

207

208

209

210

211

212

213

214

215

216

217

218

219

220

221

222

223

224

225

226

$10.8 \%(n=31 / 287)$ both types of kalemia were a concern, while for $2.4 \%(n=7 / 287)$ severe dyskalemia was not a concern. The students' answers were similar across all internship years $(\mathrm{p}=0.74)$.

There was no difference in terms of what the students had been taught regarding the danger associated with hyperkalemia versus hypokalemia. The Expert Consensus of the European Society of Cardiology has stated that hypokalemia maybe even more dangerous than hyperkalemia (14) (only 26.5\% ( $\mathrm{n}=76 / 287)$ of the students shared this opinion).

\subsubsection{Clinical cases and comparison with evidence by medicine}

The students were presented with 3 hypothetical clinical situations:

\section{1/ Isolated hypokalemia at $2.6 \mathrm{mmol} / \mathrm{L}$ (Figure 2)}

Most of the students stated that they would perform an electrocardiogram (ECG) $(79.8 \%$, $\mathrm{n}=229 / 287)$ and oral potassium supplementation $(70.7 \%, \mathrm{n}=203 / 287)$; while $16.7 \%$ $(n=48 / 287)$ would provide intravenous supplementation. Half of them $(53.7 \%, n=154 / 287)$ would request another kalemia test and 59.9\% $(\mathrm{n}=172 / 287)$ would perform additional biological tests. Only a quarter of the students $(28.6 \%, n=82 / 287)$ would undertake oral questioning and a clinical examination of the patient. They were generally not inclined to ask for advice from a specialist $(28.6 \%, \mathrm{n}=82 / 287)$. The further along the student was with their studies, the less likely they were to perform an electrocardiogram (ECG) in case of isolated hypokalemia ( $\mathrm{p}=0.0001)$. On the other hand, they would more often request additional biological tests $(\mathrm{p}=0.004)$. The students in the second year were the most inclined to supplement with potassium ( $\mathrm{p}=0.029)$ and they were the least inclined to refer their patients to the emergency department or to a hospital $(\mathrm{p}=0.025)$. There was not a statistical difference between the internship year in terms of checking the kalemia a second time $(p=0.33)$ or performing an interview and a clinical examination $(\mathrm{p}=0.47)$.

More than $50 \%$ of the students provided answers that were in keeping with the medical curriculum and with the data in the literature, except for the items "Interrogation/clinical examination" (28.6\%, $\mathrm{n}=82 / 287)$ and "Diet rich in potassium" $(1.4 \%, \mathrm{n}=4 / 287)$. The major difference lies in the way the patient would be supplemented with potassium: $70.7 \%$ ( $n=203 / 287$ ) of the patients would be given an oral supplementation in accordance with the data in the literature $(15,16)$. Indeed, interrogation, clinical examination and further investigations are essential to determine whether the patient should be hospitalized, and if so, 
227 the route of administration will be intravenous. If there is good tolerance and no signs of

228 severity, the route of administration will be oral. There is no discrepancy between curriculum 229 and expert opinion.

2/ Isolated hyperkalemia at $5.7 \mathrm{mmol} / \mathrm{L}$ (Figure 3)

Approximately three-quarters of the students indicated that they would first request another 234 kalemia test $(75.3 \%, n=216 / 287)$. An ECG was favored by 59.9\% ( $n=172 / 287)$, and slightly 235 less than half would prescribe an ion-exchange resin (44.9\%, $n=129 / 287)$ or additional 236 biological testing $(47 \%, \mathrm{n}=135 / 287)$. Very few would undertake oral questioning and a 237 clinical examination of the patient $(15.7 \%, \mathrm{n}=45 / 287)$ or ask for the opinion of a specialist 238 (20.6\%, n=59/287). Students in the first year of internship were the most likely to favor 239 performing an ECG $(\mathrm{p}<0.0001)$ and to treat the patient with Polystyrene Sulfonate 240 ( $\mathrm{p}=0.0002)$, while students in the second year were the least likely to recommend an ECG $241(\mathrm{p}<0.0001)$ and to treat with Polystyrene Sulfonate $(\mathrm{p}=0.0002)$. There was not a statistical difference between the year of study with regard to checking the kalemia a second time to rule-out false hyperkalemia ( $\mathrm{p}=0.21)$ or performing additional biological tests $(\mathrm{p}=0.098)$.

In case of true hyperkalemia (excluding false hyperkalemia secondary to hemolysis and/or delayed blood centrifugation), three items were different between the medical curriculum and the expert opinions: the students agreed with the curriculum in terms of performing an ECG $(59.9 \%, n=172 / 287)$ but also with the experts' opinions in regard to not performing additional biological examinations $(53 \%, \mathrm{n}=152 / 287)$ or prescribing Sodium Polystyrene Sulfonate $(55.1 \%, \mathrm{n}=158 / 287)$, at this level of kalemia.

3/ Hyperkalemia of $6.0 \mathrm{mmol} / \mathrm{L}$ in a patient with heart and kidney failure (Figure 4)

The answers of the students regarding the management of this situation were very heterogeneous: half of them would perform an ECG $(51.2 \%, \mathrm{n}=147 / 287,51.6 \%$ of the students would discontinue the MRA and/or ACE inhibitor ( $n=148 / 287)$, while a third would reduce their dose $(34.5 \%, n=99 / 287)$. More than a third of the students $(39.7 \%, n=114 / 287)$ stated that they would treat this hyperkalemia with an ion-exchange resin. Less than half of the students $(42.5 \%, \mathrm{n}=122 / 287)$ indicated that they would ask for specialist advice. The further along the general medicine student was with their studies, the more they favored prescribing an ion-exchange resin $(\mathrm{p}=0.023)$, and the more they would perform another check 
261 of the kalemia ( $\mathrm{p}<0.0001)$ to rule-out a false hyperkalemia (due to the sampling process e.g. 262 at home, with delayed centrifugation leading to hemolysis) and additional biological 263 examinations $(\mathrm{p}=0.024)$. There was not a statistical difference between the years of study in 264 regard to whether they would perform an ECG $(p=0.42)$ or transfer the patient to the 265 emergency department ( $\mathrm{p}=0.085)$.

266 Several items were discordant between the medical curriculum and the guidelines: the 267 students' answers were in keeping with the European guidelines to not undertake additional 268 biological examinations $(80.1 \%, \mathrm{n}=230 / 287)$. On the other hand, only $3.8 \%(\mathrm{n}=11 / 287)$ 269 followed the guidelines for "temporary" discontinuation of MRA and/or ACE, and more than $27051.6 \%(n=148 / 287)$ recommended "permanent" discontinuation. Increasing the dosage of 271 Furosemide was considered appropriate by $20.6 \%(n=59 / 287)$.

\section{Discussion}

To our knowledge, this is the first study to evaluate the competence and the perception of

277 danger of graduating French general medicine students regarding dyskalemia.

278 - The knowledge regarding the management of dyskalemia was highly variable from one 279 student to the next and according to how close they were to completion of their medical 280 degree.

281 - The thresholds for dyskalemia were not well known and there was inadequate recognition of 282 the risk associated with hypokalemia.

283 - French medical students appear to favor the use of ion exchange resins. This is specific to 284 France and probably due to what is taught in the medical curriculum.

285 - In case of hyperkalemia in the context of heart and renal failure, management was mostly 286 focused on the renal risk, while ignoring the cardiovascular benefit.

287 - The students tended to be disinclined to examine patients in case of dyskalemia.

288 - The students tended to see little merit in engaging a specialist when faced with dyskalemia.

289 - The use of ECG decreased as the studies progressed, probably because the internship in the GP's office has not yet been completed in the seventh-year initial formation. 
295 We were surprised to discover that some students considered extreme and dangerous values to be the pathological thresholds for kalemia: $2.5 \mathrm{mmol} / \mathrm{L}$ for hypokalemia and $6.5 \mathrm{mmol} / \mathrm{L}$ for 297 hyperkalemia.

298 The greatest diversity in the answers related to hyperkalemia with heart and renal failure, and 299 was dependent on the level of advancement in the specialty, especially in regard to the 300 prescription of Sodium Polystyrene Sulfonate (28.9\% of students in the first year of internship 301 versus $47.1 \%$ in the third year) and performing a second kalemia test to rule-out a false 302 hyperkalemia due to the sampling process (19.6\% in the first year versus $49.4 \%$ in the third 303 year). Four students even stated that they would stop all treatments (1.4\%), which is generally thought to be extremely dangerous for the patient.

305 306 307 308 309

In case of isolated hypokalemia, management varied also according to the years of study: students in the second year of internship were the most likely to supplement by oral administration and to not refer their patients to the emergency department, unlike the other two years. In addition, there was a difference in the way the potassium would be supplemented: $16.7 \%$ would do so intravenously versus $68.3 \%$ favoring oral administration.

In the case of isolated hyperkalemia, the approach of the seventh-year medical students was essentially to perform an ECG, to treat with Sodium Polystyrene Sulfonate, and to recheck the kalemia, whereas the approach of the ninth-year medical students was to initially only recheck the kalemia. The thresholds considered pathological are different in each laboratory, and students rely on these standards to manage hyperkalemia.

\subsection{Inadequate recognition of the risk related to hypokalemia}

The risk associated with hypokalemia is often underestimated by students. Indeed, mortality is significantly increased below a threshold of $4.1 \mathrm{mmol} / \mathrm{L}$ in case of hypertension (1) or chronic heart failure (17), and $3.9 \mathrm{mmol} / \mathrm{L}$ in case of acute heart failure after myocardial infarction (18). Several studies have also shown that hypokalemia is associated with increased mortality in heart failure (19), and that blood potassium levels below $4.0 \mathrm{mmol} / \mathrm{L}$ are associated with an increased risk of all-cause mortality, mortality from cardiovascular disease and progressive heart failure, and an increased rate of all-cause and cardiovascular hospitalizations $(9,20)$. Hypokalemia increases the risk of ventricular arrhythmia and cardiac arrest (2,21); a decrease in blood potassium by $1 \mathrm{mmol} / \mathrm{L}$ increases the risk of ventricular arrhythmia by $28 \%$ (22). In case of cardiac arrest, kalemia is thought to be significantly lower than in controls, and survivors are often hypokalemic (23-25). 
There is a U-shaped relationship between kalemia and all-cause mortality, and levels of potassium that are considered "normal" are also associated with an increased risk of death. In general, the more the potassium level deviates from normal, the higher the mortality (1).

\subsection{Widespread use of ion-exchange resins}

French general medicine students are taught to use Sodium Polystyrene Sulfonate (SPS), which is an ion-exchange resin. This is in accordance with the practices of French doctors, who use SPS much more frequently than their German, Italian, Spanish, and English colleagues (26). However, there is no evidence regarding the efficacy of SPS in the emergency treatment of hyperkalemia $(27,28)$. The optimal rate of correction for hyperkalemia is unknown, and the relevance of an immediate decrease of kalemia in patients without cardiac manifestations of hyperkalemia has not been demonstrated (29). Additionally, this drug has not been rigorously evaluated in clinical trials to prove its efficacy and safety in acute or chronic hyperkalemia (30). Since the counter-exchange ion is sodium, extreme caution should be taken in patients with heart failure, as such patients cannot tolerate even a small increase in sodium load (30). It should be noted that SPS has marketing authorization (MA) in France for medical services rendered that are considered important. This drug was indicated as a first-line treatment for hyperkalemic patients in the French medical curriculum (12) at the time that the questionnaire was distributed (June 2017). This has been modified in the new version of the curriculum released in 2018 by the University College of Nephrology Teachers (version 8), which no longer considers SPS as a necessity but as an option in case of hyperkalemia. Of importance, none of the new-generation potassium binders is reimbursed in France to date, therefore preventing from any related teaching process.

\subsection{Management of hyperkalemia in heart and renal failure}

The management of hyperkalemia by French general medicine students differs quite considerably from the European guidelines. They tend to discontinue ACE inhibitors and/or MRAs without considering reintroducing them, which can adversely affect patients as the morbi-mortality increases without the use of an optimal dose of these drugs (30-32). Trevisan et al. have shown that after hyperkalemia, $47 \%$ of MRA treatments are halted, and they are not reintroduced in $76 \%$ of cases (33). Discontinuation of RAAS inhibitor therapy is associated with an increased risk of cardiovascular morbidity and mortality and total mortality (14). The European guidelines in regard to heart failure tolerate a maximum hyperkalemia threshold of $6.0 \mathrm{mmol} / \mathrm{L}$. Above this limit, RAAS inhibitors should be discontinued for a 
time, but not definitively; between 5.5 and $6.0 \mathrm{mmol} / \mathrm{L}$, there can be brief discontinuation or 363 dose reduction $(13,14)$. Thus, the European guidelines emphasize the need to try to reintroduce RAAS inhibitors as soon as possible, when they have been temporarily halted or the dosage decreased due to hyperkalemia, with close monitoring of kalemia and renal function (13). Increasing the dosage of furosemide, considered as appropriate by $20 \%$ of the students, is an acceptable solution in case of hyperkalemia, but it should however be avoided in case of AKI and signs of dehydration.

369 The management is in accordance with what is taught in the Nephrology module of the medical school curriculum in the chapter entitled "Potassium balance abnormalities" (12). This is theory-based teaching that does not consider the complexity encountered in case of comorbidities such as the association with heart failure, and which recommends, in the case of moderate hyperkalemia, "eviction of hyperkalemic drugs", without their subsequent reintroduction. The risk/benefit ratio of hyperkalemia is not emphasized in teaching, and general medicine students tend to refer to "Primum Non Nocere", which is a concept that has become obsolete.

On the other hand, in the chapter regarding how to treat chronic renal failure, the possibility of "temporary" discontinuation of ACE inhibitors or ARA2 is discussed, without any reference to anti-aldosterone drugs, which are not mentioned in the curriculum. However, this information is too "diluted" to be taken in by the students, especially as it contradicts the information in the chapter "Potassium balance abnormalities".

382 Medical students are faced with contradictions that are even more prejudicial, as there is no 383 clear consensus regarding the management of these patients with cardio-renal syndrome in general practice. The fear of inducing serious secondary effects (hyperkalemia, deterioration of renal function) has led some doctors to avoid RAAS inhibitors (6), without considering the demonstrated benefit of these molecules on morbi-mortality in the event of heart failure (5, 34,35). Moreover, the use of RAAS inhibitors in France is low compared to Germany, Italy, Spain, and the United Kingdom (26). For this reason, the use of new experimental potassium chelating agents (patiromer or sodium zirconium cyclosilicate (ZS-9)) could be an option in the near future to compensate for this under-prescription (36-40). These drugs have a European MA but are not presently available in France.

\subsection{Limited use of interrogation and clinical examination}

394 Surprisingly, we found that the students were very rarely inclined to carry out an interrogation and clinical examination of patients with dyskalemia, even though this is generally considered 
to be essential during a medical consultation. In case of dyskalemia, it is crucial to identify any dietary issues and clinical elements associated with dyskalemia and to provide advice accordingly. Very few students introduce, and therefore explain to the patient, a potassiumrich diet in case of hypokalemia, whereas it is recommended in association with supplementation $(41,42)$.

\subsection{Limited use of specialists}

The students indicated that they would rarely request specialist advice and rarely refer their patients to hospitals or emergency departments in case of isolated dyskalemia. They are inclined to manage these situations on their own, especially if they are advanced in their studies. The use of specialists and hospitalization is also low among practicing GPs, ranging from 5.8 to $6.6 \%$ according to the study (43-45).

\subsection{Use of the ECG}

For isolated dyskalemia discovered in general practice, students in the first year of internship more often recommend performing an ECG than those in the following two years of study. This may be a result of the internship with a general practitioner. Indeed, although the availability of the required equipment in doctors' offices varies from $49 \%$ to $86 \%$ according to the study, the frequency of their use is at least once a week for half of the doctors who have an ECG device available $(46,47)$. Moreover, an ECG is not a very sensitive indicator of the severity of dyskalemia. Cardiac manifestations may be non-specific or absent at potassium concentrations that are associated with a risk of mortality (29). In case of hyperkalemia, an ECG is recommended above $6.0 \mathrm{mmol} / \mathrm{L}$ (29), whereas in case of hypokalemia, it is recommended for all patients, irrespective of their potassium level (49).

\subsection{Strengths and limitations of the study}

The main strength of this study lies with the use of an open-ended questionnaire, which ensured that there were no leading questions.

We limited the potential for bias by clearly explaining the objectives of the study and how the questionnaire was to be filled out before completing it. The questionnaires were filled out in the presence of a friendly and neutral team, without direct intervention but with immediate availability of assistance if required (self-administered questionnaire). 
429 Methodological bias was minimized by providing resources to organize the task of collecting,

430 analyzing, and processing the information. The questions asked were intended to be 431 straightforward, short, neutral, and without ambiguity.

432 Naturally, sample selection bias cannot be fully ruled out, although we are confident that we 433 were able to ensure adequate representativity of the population of students enrolled in French 434 general medicine studies.

435 The bias linked to the "experience" of the general medicine students could be assessed by the 436 last question, although this question contained ambiguities. In June 2017, the students who 437 had just started a new stage of internship on May $1^{\text {st }}$ did not necessarily include this in their 438 answer. Indeed, "current or ongoing internships" was not specified. There was, therefore, a 439 loss of information.

440 The questionnaire is not without its limitations, but overall, we avoided many of the potential 441 biases by excluding any leading questions and by reducing the time needed to complete the 442 questionnaire. The questions were open-ended so as not to suggest possible answers to the 443 situations described.

444 In conclusion, the validity of the results clearly needs to take into account the limitations 445 mentioned above, but these do not significantly detract from the coherence and overall 446 meaning of the results.

447

449 The medical curriculum cannot always take into account the complex situations experienced 450 in clinical practice. Our study points out a lack of coherence between what is taught regarding 451 the management of dyskalemia and the guidelines regarding patients with heart and renal 452 failure. This often results in inadequate management and a reluctance to reintroduce drugs 453 prone to induce hyperkalemia (ACE/ARA2 and MRA) after an initial episode of 454 hyperkalemia. This at least in part explains why France has the lowest level of RAAS 455 inhibitor use in Europe (27), and why these drugs are often used at a suboptimal dosage in 456 heart failure. This is quite the opposite in case of chronic kidney insufficiency, for which 457 France has the highest level of RAAS inhibitor use in Europe (50).

458 It is essential for medical students to very early on be faced with complex situations in the 459 management of cardio-renal syndrome, due to the increasing prevalence of this syndrome 460 among older patients with diabetes, heart failure, and kidney disease. 
461

462

463

464

465

466

467

468

469

470

471

472

473

474

475

476

477

478

479

480

481

482

483

484

485

486

487

488

489

490

491

492

Medico-administrative data such as the SNDS (Système National de Données de Santé) are collected by the Primary Health Insurance in France, but the tools proposed to SNDS users make their in-depth exploitation difficult. A view based on a generic model of care trajectories could make it possible to identify situations in which the trajectory of care can be improved (e.g., severe hypokalemia, severe hyperkalemia) and thus serve as a basis for more pragmatic teaching, adapted to general practitioners. (51)

Indeed, the recent opening of access to the French nationwide health record database SNDS is a great opportunity to carry out comprehensive health studies at the country level. Happe and Drezen have proposed a toolbox to query and cope with the complexity of care pathways of patients, because access is very difficult for nonexpert data scientists. This toolbox is particularly suitable for understanding timeline representations of individual patient healthcare trajectories in case of heart failure and cardiorenal syndrome. (52)

It would also be appropriate to standardize the guidelines and the curriculum in order to provide pragmatic instruments to help with the management of dyskalemia in patients with heart failure and kidney disease, either as a decision tree or a dedicated computer tool.

\section{References}

1) Krogager ML, Torp-Pedersen C, Mortensen RN, et al. Short-term mortality risk of serum potassium levels in hypertension: a retrospective analysis of nationwide registry data. Eur Heart J. 2017 Jul; 38(2):104- 12.

2) Macdonald JE, Struthers AD. What is the optimal serum potassium level in cardiovascular patients? J Am Coll Cardiol. 2004 Jan 21; 43(2):155- 61.

3) Nilsson E, Gasparini A, Ärnlöv J, et al. Incidence and determinants of hyperkalaemia and hypokalaemia in a large healthcare system. Int J Cardiol. 2017 Oct 15; 245:277- 84.

4) Pitt B, Bakris G, Ruilope LM, DiCarlo L, Mukherjee R, on Behalf of the EPHESUS Investigators. Serum Potassium and Clinical Outcomes in the Eplerenone Post-Acute 
493 Myocardial Infarction Heart Failure Efficacy and Survival Study (EPHESUS). Circulation. 4942008 Oct $14 ; 118(16): 1643-50$.

495

5) Zannad F, McMurray JJV, Krum H, et al. Eplerenone in Patients with Systolic Heart 497 Failure and Mild Symptoms. N Engl J Med. 2011 Jan 6; 364(1):11- 21.

498

499 6) Rossignol P, Zannad F, Pitt B. Time to retrieve the best benefits from renin angiotensin 500 aldosterone system (RAAS) inhibition in heart failure patients with reduced ejection fraction: 501 Lessons from randomized controlled trials and registries. Int J Cardiol. 2014 502 Dec;177(3):731- 3.

503

504 505

7) Rossignol P, Dobre D, McMurray JJV, et al. Incidence, determinants, and prognostic 506 significance of hyperkalaemia and worsening renal function in patients with heart failure

507 receiving the mineralocorticoid receptor antagonist eplerenone or placebo in addition to 508 optimal medical therapy: results from the Eplerenone in Mild Patients Hospitalization and 509

8) Zannad F, Stough G, Rossignol P, et al. Mineralocorticoid receptor antagonists for heart failure with reduced ejection fraction: integrating evidence into clinical practice. Eur Heart $\mathbf{J}$. 2012 Nov; 33(22):2782-95.

513

9) Ahmed A, Zannad F, Love TE, et al. A propensity-matched study of the association of low serum potassium levels and mortality in chronic heart failure. Eur Heart J. 2007 Jun; 28(11):1334-43.

10) Durrieu G, Hurault C, Damase-Michel C, Montastruc JL. Perception of risk of adverse drug reactions: a 3-year follow-up of a cohort of medical students. Fundam Clin Pharmacol. 2010 Aug;24(4):423-7.

522 11) A. Bouletreau, D. Chouaniere, P. Wild, J.M. Fontana. Concevoir, traduire et valider un 523 questionnaire. A propos d'un exemple, EUROQUEST. [Rapport de recherche] Notes

524 scientifiques et techniques de l'INRS NS 178, Institut National de Recherche et de Sécurité 525 (INRS). 1999, 46 p., ill., bibliogr. ffhal01420163f. 
526 12) Collège Universitaire des Enseignants de Néphrologie, auteurs. Néphrologie. $6^{\text {ème }}$ édition. 527 Paris : Ellipses ; 2014.

528

529

530

531

532

533

534

535

536

537

538

539

540

541

542 543

544

545

546

547

548

549

550

551

552

553

554 20) Rossignol P, Girerd N, Bakris G, et al. Impact of eplerenone on cardiovascular outcomes 555 in heart failure patients with hypokalaemia. Eur J Heart Fail. 2017 Jun; 19(6):792-799.

13) Ponikowski P, Voors AA, Anker SD, et al. ESC Guidelines for the diagnosis and treatment of acute and chronic heart failure: The Task Force for the diagnosis and treatment of acute and chronic heart failure of the European Society of Cardiology (ESC)Developed with the special contribution of the Heart Failure Association (HFA) of the ESC. Eur Heart J. 2016 Jul 14; 37(27):2129- 200.

14) Rosano et al. Expert consensus document on the management of hyperkalaemia in patients with cardiovascular disease treated with renin angiotensin aldosterone system inhibitors: coordinated by the Working Group on Cardiovascular Pharmacotherapy of the European Society of Cardiology. Cardiovascular pharmacotherapy. Eur Heart J. 2018;4(3):180-188.

15) Staple B, Fleming S. Management of Hypokalaemia Clinical Guideline V2.0. Royal Cornwall Hospitals NHS Trust. August 2019.

16) Rastergar A, Soleimani M. Hypokalaemia and hyperkalaemia. Postgrad Med J. 2001 Dec; 77(914):759-764.

17) Aldahl M, Jensen AC, Davidsen L, et al. Associations of serum potassium levels with mortality in chronic heart failure patients. Eur Heart J. 2017 Oct 7; 38(38):2890-2896.

18) Krogager ML, Eggers-Kaas L, Aasbjerg K, et al. Short-term mortality risk of serum potassium levels in acute heart failure following myocardial infarction. Eur Heart J. 2015 Oct; $1(4): 245-51$.

19) Cleland JG, Dargie HJ, Ford I. Mortality in heart failure: clinical variables of prognostic value. Br Heart J. 1987 Dec; 58(6) 572-82. 
557 21) Schulman M, Narins RG. Hypokalaemia and cardiovascular disease. Am J Cardiol. 1990

558 Mar 6; 65(10):4E-9E.

559

560 22) Cohen JD, Neaton JD, Prineas RJ, Daniels KA. Diuretics, serum potassium and 561 ventricular arrhythmias in the Multiple Risk Factor Intervention trial. Am J Cardiol 1987 Sep $562 \quad 1 ; 60(7): 548-54$.

563 23) Salerno DM, Asinger RW, Elsperger J, Ruiz E, Hodges M. Frequency of hypokalaemia 564 after successfully resuscitated out-of- hospital cardiac arrest compared with that in transmural 565 acute myocardial infarction. Am J Cardiol. 1987 Jan 1; 59(1):84-8.

24) Johnson CJ, Peterson DR, Smith EK. Myocardial tissue concentrations of magnesium and 567 potassium in men dying suddenly from ischemic heart disease. Am J Clin Nutr. 1979 May; 568 32(5): 967-70.

569

25) Kjeldsen K. Hypokalaemia and sudden cardiac death. Exp Clin Cardiol. 2010; 15(4):e96570 e99.

571 26) Rossignol P, M Ruilope L, Cupisti A, et al. Recurrent hyperkalaemia management and 572 use of renin- angiotensin-aldosterone system inhibitors. A European multi-national targeted 573 chart review. Clinical Kidney Journal. 2019 Sept 30: 1-6.

574 27) Mahoney BA, Smith WA, Lo DS, Tsoi K, Tonelli M, Clase CM. Emergency interventions 575 for hyperkalaemia. Cochrane Database Syst Rev. 2005 Apr 18;(2).

576 28) Elliott MJ, Ronksley PE, Clase CM, Ahmed SB, Hemmelgarn BR. Management of 577 patients with acute hyperkalaemia. CMAJ. 2010 Oct 19; 182(15):1631-1635.

578 29) Rossignol P, Legrand M, Kosiborod M, et al. Emergency management of severe 579 hyperkalaemia: Guideline for best practice and opportunities for the future. Pharmacol Res. 5802016 Nov; 113:585- 91.

581 30) Epstein M, Reaven NL, Funk SE, McGaughey KJ, Oestreicher N, Knispel J. Evaluation 582 of the treatment gap between clinical guidelines and the utilization of renin-angiotensin583 aldosterone system inhibitors. Am J Manag Care. 2015; 21(11):212-220 
31) Beusekamp JC, Tromp J, van der Wal HH, et al. Potassium and the use of reninangiotensin-aldosterone system inhibitors in heart failure with reduced ejection fraction: data from BIOSTAT-CHF. Eur J Heart Fail. 2018 May; 20(5):923-930.

32) Ouwerkerk W, Voors AA, Anker SD, et al. Determinants and clinical outcome of uptitration of ACE-inhibitors and beta-blockers in patients with heart failure: a prospective Eu3) Trevisan $\mathrm{M}$, de Deco $\mathrm{P}, \mathrm{Xu} \mathrm{H}$, et al. Incidence, predictors and clinical management of hyperkalaemia in new users of mineralocorticoid receptor antagonists. Eur J Heart Fail. 2018; 20(8):1217-1226.

34) Pitt B, Zannad F, Remme W, et al. The effect of spironolactone on morbidity and mortality in patients with severe heart failure. Randomized Aldactone Evaluation Study Investigators. N Engl J Med. 1999; 341(10):709-717.

35) Pitt B, Remme W, Zannad F, et al. Eplerenone, a Selective Aldosterone Blocker, in Patients with Left Ventricular Dysfunction after Myocardial Infarction. N Engl J Med 2003; 348(14):1309-1321.

36) Agarwal R, Rossignol P, Romero A, et al. Patiromer versus placebo to enable spironolactone use in patients with resistant hypertension and chronic kidney disease (AMBER): a phase 2, randomized, double-blind, placebo-controlled trial. Lancet. 2019 Sept.

37) Pitt B, Bakris GL, Bushinsky DA, et al. Effect of patiromer on reducing serum potassium and preventing recurrent hyperkalaemia in patients with heart failure and chronic kidney disease on RAAS inhibitors. Eur J Heart Fail. 2015 Oct; 17(10):1057-65.

38) Weir MR, Bakris GL, Bushinsky DA, et al. Patiromer in patients with kidney disease and hyperkalemia receiving RAAS inhibitors. N Engl J Med. 2015 Jan 15; 372(3):211-21.

39) Anker SD, Kosiborod M, Zannad F, et al. Maintenance of serum potassium with sodium zirconium cyclosilicate (ZS-9) in heart failure patients: results from a phase 3 randomized, double-blind, placebo-controlled trial. Eur J Heart Fail. 2015 Oct; 17(10):1050-6.

40) Rafique Z, Peacock WF, LoVecchio F, Levy PD. Sodium zirconium cyclosilicate (ZS-9) for the treatment of hyperkalemia. Expert Opin Pharmacother. 2015; 16(11):1727-34. 
613 41) Viera A, Wouk N. Potassium Disorders: Hypokalaemia and Hyperkalaemia. Am Fam 614 Physician. 2015 Sept 15; 92(6):487-495.

615 42) Cohn JN, R. Kowey PR, K. Whelton PK, Prisant LM. New Guidelines for Potassium 616 Replacement in Clinical Practice. A Contemporary Review by the National Council on 617 Potassium in Clinical Practice. Arch Intern Med; 2000 Sep 11; 160(16):2429-36.

618 43) Existe-t-il une typologie des actes effectués en médecine générale ? Rev Prat Med Gen $6192004 ; 656 / 657: 781-84$.

620 44) Gallais JL. Actes et fonctions du médecin généraliste dans leurs dimensions médicales et 621 sociales. Doc Rech Med Gen. $1997 ; 45$.

622 45) Évaluation des recours demandés par les médecins généralistes à leurs confrères des 623 autres spécialités. Collège des généralistes enseignants du Poitou-Charentes. 1994.

46) Le Goaziou M-F. L’équipement du cabinet médical. Exercer. 2003 ;67 :20-26.

625

47) Robin C. Etat des lieux de la pratique de l'électrocardiogramme en médecine générale en 627 Picardie. [Thèse pour l'obtention du diplôme d'Etat de docteur en médecine]. Amiens : 628 Université de Picardie Jules Verne Faculté de Médecine ; 2018.

629

630 48) Lehel A. Exercice de la médecine générale avec ou sans électrocardiogramme. [Thèse 631 pour l'obtention du diplôme d'Etat de docteur en médecine]. Bordeaux : Université de 632 Bordeaux UFR des sciences médicales ; 2015.

633

49) Kardalas E, Paschou SA, Anagnostis P, Muscogiuri G, Siasos G, Vryonidou A. 635 Hypokalaemia: a clinical update. Endocrine Connections. 2018 Apr; 7(4):135-146.

636

637 50) Pecoits-Filho R. et al. Prescription of renin-angiotensin-aldosterone system inhibitors 638 (RAASi) and its determinants in patients with advanced CKD under nephrologist care. J Clin 639 Hypertens (Greenwich). 2019 Jul; 21(7):991-1001. 
645 52) Happe A, Drezen E. A visual approach of care pathways from the French nationwide

646 SNDS database - from population to individual records: the ePEPS toolbox. Fundam Clin

647 Pharmacol. 2018 Feb;32(1):81-84.

648

649

650

651

652

653

654

655

656

657

658

659

660

661

662

663

664

665

666

667

668

669

670

671

672

673

674

675

676

677

678

679

680

681

682

683

684

685

686

687

\section{a. Contributorship statement:}

Lisa Senninger: Research design, data collection, data entry, writing.

Laure Abensur-Vuillaume: Proofreading, partial writing

Luc Frimat: Proofreading, partial writing

Nicolas Girerd: Proofreading, partial writing

Zohra Lamiral: statistical review

Patrick Rossignol: Proofreading, partial writing

Jean-Marc Boivin: Research design, Proofreading, partial writing

b. Competing interests: none related to the present manuscript. Outside, and relevant to the topic addressed (potassium binders): Patrick Rossignol reports consulting activities including (advisory boards, steering committees) with Relypsa/Vifor/Vifor Fresenius Medical care.

c. Funding: none

d. Data sharing statement: All data are available on request to the corresponding author.
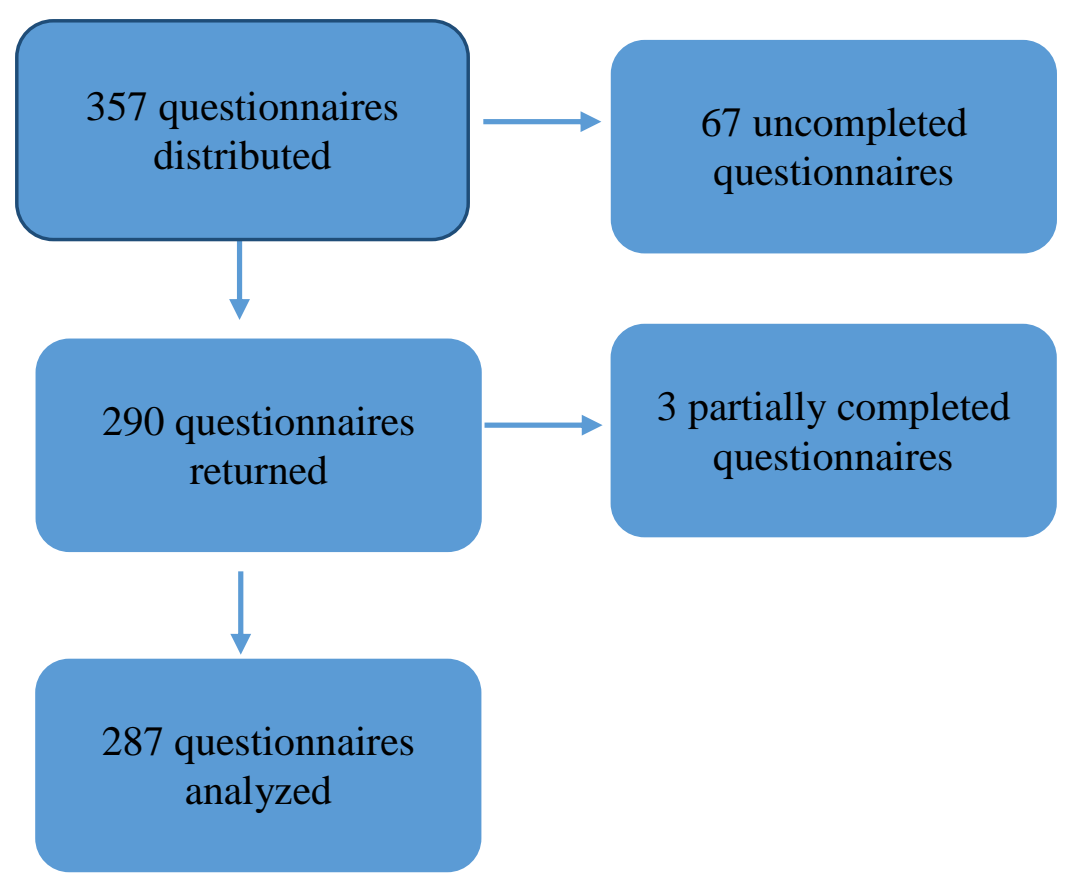

Figure 1: Flowchart of the participants 
In a otherwise healthy patient (i.e with no

history of comorbidities) with not any

treatment, you discover a kalemia of

$2.6 \mathrm{mmol} / \mathrm{L}$ during a routine check-up

What is (are) your reaction(s) in terms of

drug prescriptions, investigations, specialist

advice?

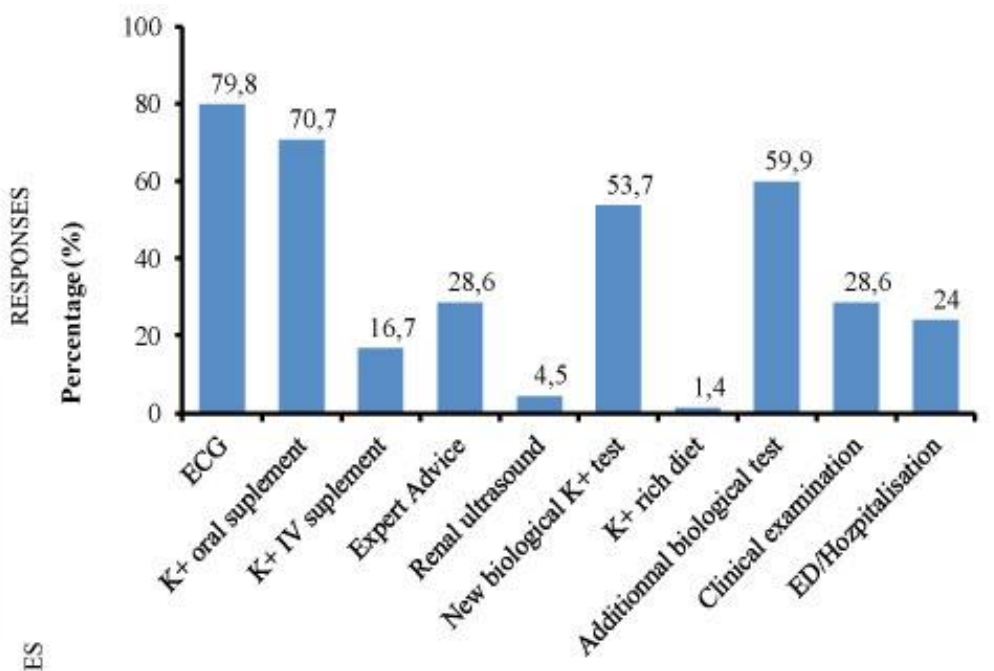

Figure 2: Hypokalemia of $2.6 \mathrm{mmol} / \mathrm{L}$ in a patient who is not on any treatment: student's

698 The radar chart is represented by student's answers in green, curriculum in red, and expert 699 opinion in grey.

700 Legend: IV (intravenous), ED (emergency department). 


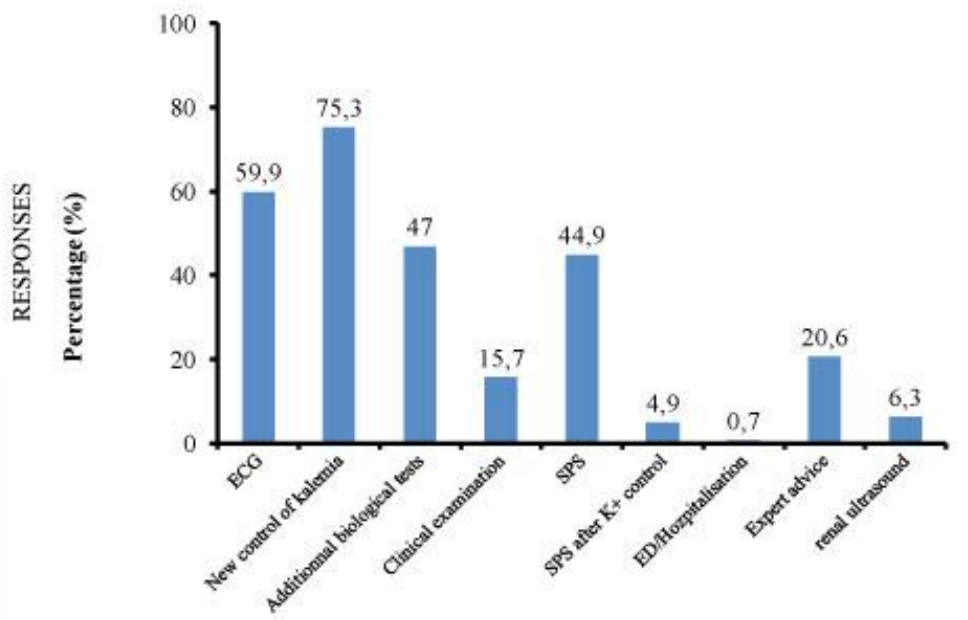

711 Figure 3: Hyperkalemia of $5.7 \mathrm{mmol} / \mathrm{L}$ in a patient who is not on any treatment:

712 student's responses and comparison with expert opinions and curriculum

713 The radar chart is represented by student's answers in green, curriculum in orange, and 714 expert opinion in blue.

715 Legend: ARM (Angiotensin Receptor Agonist), ACE (Angiotensin-comverting enzyme 716 inhibitors), SPS (Sodium Polystyrene sulfate), ED (emergency department). 

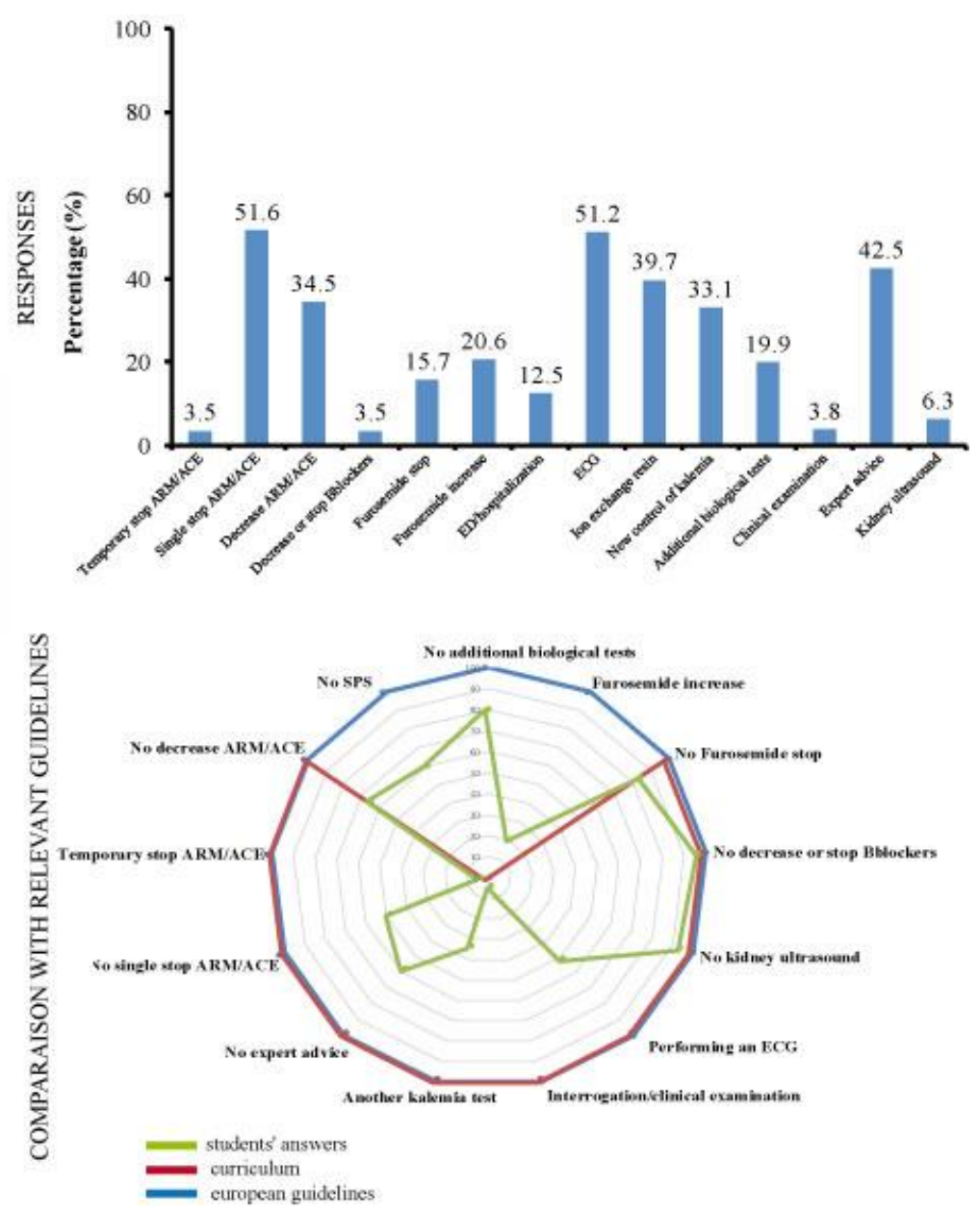

Figure 4: Hyperkalemia of $6.0 \mathrm{mmol} / \mathrm{L}$ in a patient with heart and kidney failure, student's responses and comparison with European guidelines and curriculum

The radar chart is represented by student's answers in green, curriculum in red, and expert

731 opinion in blue.

732 Legend: ARM (Angiotensin Receptor Agonist), ACE (Angiotensin-converting enzyme

733 inhibitors), SPS (Sodium Polystyrene sulfate), ED (emergency department), GFR (Glomerular 734 filtration rate), HF (Heart failure), CKD (Chronic kidney disease). 


\begin{tabular}{|c|c|c|c|c|c|c|c|c|c|}
\hline \multirow[b]{2}{*}{ Year } & \multirow[b]{2}{*}{$\mathrm{n}=287$} & \multicolumn{4}{|c|}{ Hyperkalemia threshold } & \multicolumn{4}{|c|}{ Hypokalemia threshold } \\
\hline & & $\begin{array}{c}K<5 \\
17(5.9 \%)\end{array}$ & $\begin{array}{c}K=5 \\
192(66.9 \%)\end{array}$ & $\begin{array}{l}5<K \leq 5.5 \\
71(24.7 \%)\end{array}$ & $\begin{array}{r}K>5.5 \\
7(2.4 \%)\end{array}$ & $\begin{array}{c}K<3 \\
8(2.8 \%)\end{array}$ & $\begin{array}{l}3 \leq K<3.5 \\
53(18.5 \%)\end{array}$ & $\begin{array}{c}K=3.5 \\
224(78 \%)\end{array}$ & $\begin{array}{l}K>3.5 \\
2(0.7 \%)\end{array}$ \\
\hline $1^{\text {st }}$ & $\mathrm{n}=97$ & $\begin{array}{c}10 \\
(18.2 \%) \\
\end{array}$ & $72(74 \%)$ & $11(11.3 \%)$ & $4(4.1 \%)$ & $4(4.1 \%)$ & $16(16.5 \%)$ & $76(78.4 \%)$ & $1(1 \%)$ \\
\hline $2^{\text {nd }}$ & $\mathrm{n}=103$ & $6(5.8 \%)$ & $61(59.2 \%)$ & $34(33 \%)$ & $2(1.9 \%)$ & $3(2.9 \%)$ & $17(16.5 \%)$ & $82(79.6 \%)$ & $1(1 \%)$ \\
\hline \multirow[t]{2}{*}{$3^{\text {rd }}$} & $\mathrm{n}=87$ & $1(1.1 \%)$ & $59(67.8 \%)$ & $26(29.9 \%)$ & $1(1.1 \%)$ & $1(1.1 \%)$ & $20(23 \%)$ & $66(79.5 \%)$ & $0(0 \%)$ \\
\hline & & \multicolumn{4}{|c|}{$p=0.0005$} & \multicolumn{4}{|c|}{$p=0.85$} \\
\hline
\end{tabular}

739

740

741

742 Table 1: Hyperkalemia and hypokalemia threshold (mmol/L) according to the years of 743 study.

744

745 